
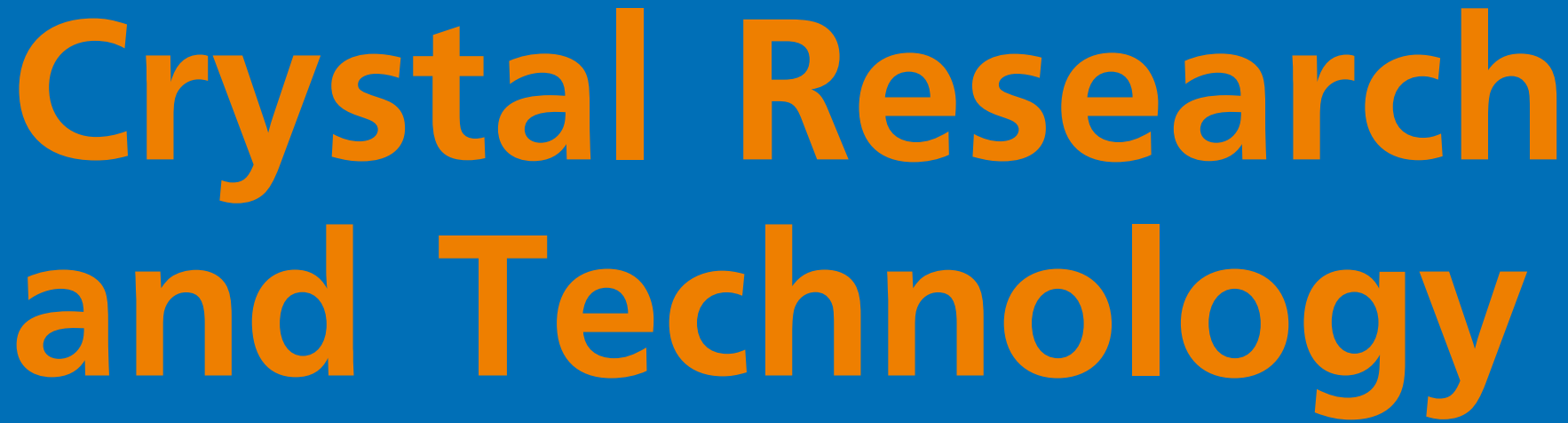

Journal of Experimental and Industrial Crystallography

Zeitschrift für experimentelle und technische Kristallographie

Established by

W. Kleber and H. Neels

Editor-in-Chief

W. Neumann, Berlin

Consulting Editor

K.-W. Benz, Freiburg

Editor's Assistant

H. Kleessen, Berlin
Editorial Board

R. Fornari, Berlin

P. Görnert, Jena

M. Watanabe, Tokyo

K. Sangwal, Lublin 


\title{
Effects of forced solution flow on lysozyme crystal growth
}

\author{
Yong Yu**1, Yuhong Liu ${ }^{1}$, Xuan Wang ${ }^{1}$, D. Oberthür ${ }^{2}$, K. Dierks ${ }^{2}$, and C. Betzel ${ }^{2}$ \\ ${ }^{1}$ Key Laboratory of Microgravity (National Microgravity Laboratory), Institute of Mechanics, Chinese \\ Academy of Sciences, Beijing 100190, P. R. China \\ 2 Institute of Biochemistry and Molecularbiology, University of Hamburg, c/o DESY, Hamburg 22603 , \\ Germany
}

Received 14 December 2009, revised 18 January 2010, accepted 20 January 2010

Published online 29 January 2010

Key words protein crystallization, fluid flow, impurities, mass transfer, lysozyme.

In order to study quantitatively the effects of forced solution on crystal growth, we designed a new set of experimental equipment, in particular, a microchannel mixer was used as crystallization container so that the consumption of protein samples was much reduced and thus an exact syringe pump could be used for precise control of the flow rates. Since the mixer's section was designed to be rectangular, the solution velocity in its center was steady and constant, and thus repeatable experiments were facilitated. Experimental results showed that the effects of forced solution on protein crystal growth were different under different levels of supersaturation, and new results were obtained for cases of high supersaturation. When the supersaturation is $\sigma=2.3$, with increasing flow rates the growth rates of the lysozyme crystal's (110) face hardly change when the flow rates are lower than $1300 \mu \mathrm{m} / \mathrm{s}$, and decrease quickly afterwards. When the flow rate reaches $2000 \mu \mathrm{m} / \mathrm{s}$, the crystal nearly ceases to grow. When the supersaturation is $\sigma=2.7$, with increasing flow rates the (110) face growth rates increase at the beginning then reach the maximum values at $1700 \mu \mathrm{m} / \mathrm{s}-$ $1900 \mu \mathrm{m} / \mathrm{s}$ and decrease afterwards, approaching zero or so when the flow rate reaches $12000 \mu \mathrm{m} / \mathrm{s}$. The higher the supersaturation, the larger the flow rate at which the crystal ceases to grow.

(C) 2010 WILEY-VCH Verlag GmbH \& Co. KGaA, Weinheim

\section{Introduction}

Obtaining large and high-quality protein single crystals is the bottleneck for using X-ray diffraction to determine the three-dimensional structure of a protein. Mass transfer and crystal growth kinetics have been studied for overcoming this difficulty [1]. Crystallization is inherently unable to maintain a state of equilibrium as it creates a solute concentration gradient which may lead to a buoyancy-driven flow in the gravitational field [2], which is thought to be detrimental to protein crystal growth, because the forced flow will influence the steady-state protein concentration gradient around the growing protein crystal and destroy its mass filtering capability [3]. Space was thought as a perfect environment for the production of high quality protein crystal because the sedimentation movement and convective flow due to gravity are negligible under microgravity conditions [4,5]. A number of experiments carried out in space aircrafts have produced some crystals that were relatively large and well ordered compared with that grown on earth. However, there have also been a lot of crystals produced in space experiments that have no noticeable improvement in quality and internal structure compared with those grown on earth [6-8].

The solution flow can reduce the growth rate of a protein crystal [9], however, the influence of the forced flow is unlikely to reduce the growth rate of a rhombohedral lysozyme to zero [10]. It was thought that the shear force arising from the fluid flow impeded the protein growth [9]. However, M. L. Grant and D. A. Saville [11] studied the role of transport phenomena in the protein growth and found that the shear force arising from the fluid flow could not alter the state of the protein near the crystal surface. The reduction of protein diffusion rate due to counter-diffusion of precipitant was small, which could not retard the protein growth and thus the contaminant brought by convection was thought to be the major reason in the reduction of growth rate.

* Corresponding author: e-mail: yuyong@imech.ac.cn 
According to a two-dimensional model, the velocity, concentration and growth rate distributions were obtained numerically using a finite volume method at a higher supersaturation condition [12], which showed that convection is the dominant factor in solute transport. The study of Peter G. Vekilov et al. [13] showed that the growth rate and step velocity underwent fluctuations, which was the result of coupled bulk transport and nonlinear interface kinetics. Another experiment showed that the growth of lysozyme was dominated by interfacial kinetics rather than bulk transport, and the effect of convection on lysozyme crystal growth had a tendency to increase with the increase of supersaturation [14].

Forced solution flow has been employed in protein crystallization experiments [15-20] to investigate quantitatively the effects of solution convection on protein crystal growth. Rosenberger et al. designed a solution circulation loop, including a circinal cell and a peristaltic pump [13,15], and found from experiments that whether the growth rates increased depended on the flow rates and purity of lysozyme. For example, the face growth rate increased initially (flow rates $\mu<250 \mu \mathrm{m} / \mathrm{s}$ ) and then decreased (flow rates $\mu>250 \mu \mathrm{m} / \mathrm{s}$ ) with increasing flow rate in high-purity solution, whereas the (110) face growth deceleration occurred at any flow rates in low-purity lysozyme $(\approx 95 \%)$. It was thought that convective transport increased the interfacial concentration of impurities and thus reduced the growth rate and even brought the growth rate to nearly zero. Akio Kadowaki et al. found that the crystal quality grown under forced flow was better than that grown in quiescent conditions [17]. Further AFM studies demonstrated that the flow changed the surface morphology drastically. For crystals grown under forced flow condition, the step density is higher and the step growth rates are lower compared with those grown under quiescent condition $[18,19]$. At present, there is no further explanation why the forced flow can enhance the crystal quality, and thus the influence of convection transport on the crystal growth is unclear.

Microfluidics has been used to explore various methods and conditions for facilitating protein crystallization. This technique can minimize the amount of protein sample consumed and reduce the labor involved so that the protein crystallization becomes simple and economical [20-23]. For studying the effects of forced flow on protein crystal growth, it is important to control the flow rates in the crystallization container precisely. Although the exact syringe pump can provide a precise flow control, it consumes a lot of protein solution because the protein solution could not be used circularly. Hence the microfluidics technique should be used to remedy this shortcoming.

In this article we describe newly designed equipment for studying the effects of forced solution on protein crystal growth, including a two T-junction microchannel mixer used as the crystallization container made from PMMA and an exact syringe pump used for precisely controlling the flow rates in the crystallization container. With this equipment, the effects of forced solution on the (110) face growth of lysozyme crystal were studied quantitatively.

\section{Material and approach}

The HAc-NaAc buffer solution ( $50 \mathrm{mmol} / \mathrm{L}, \mathrm{pH} 4.5)$ was used, chicken egg-white lysozyme was purchased from AMRESCO company (Lot \#:2436B048, USA) and silver staining solution was purchased from Beyotime company (P0017S, China). High-purity deionized water $(18.2 \mathrm{M} \Omega$ ) was obtained by passing distilled water through a Milli-Q Plus water purification system, and all other reagents were of analytical grade.

Two T-junction microchannel mixer made from PMMA was designed as the crystallization cell, as shown in figure 1, where there are four entrances and one exit: 1-entrance for lysozyme solution, 2-for $\mathrm{NaCl}$ solution, 3 -for lysozyme solution, 4-for $\mathrm{NaCl}$ solution and 5-exit. The widths of microchannels at the entrances are $500 \mu \mathrm{m}$ and the width of microchannel at the location where flows came from the four entrances converge are $1000 \mu \mathrm{m}$. There are two protuberances $10 \mathrm{~mm}$ from the four flows intersection point, and the protuberance's length and width are $5 \mathrm{~mm}$ and $750 \mu \mathrm{m}$, respectively. The distance between two protuberances is $1 \mathrm{~mm}$, and the width of microchannels at the protuberances is $250 \mu \mathrm{m}$. The depth of the microchannel is $200 \mu \mathrm{m}$. Place 6 is the location for observation, which is at a distance of about $20 \mathrm{~mm}$ from the exit.

The lysozyme and $\mathrm{NaCl}$ solutions, driven by a syringe pump, flowed into the microchannel, passed the two protuberances and then came to a straight segment where the crystal was grown. The flow was designed to be disturbed by the two protuberances so that lysozyme and $\mathrm{NaCl}$ solutions can be better mixed. To ensure the stability of the solution concentration, those solutions that flowed out of the microchannel wouldn't be further utilized. The section of the microchannel is rectangular rather than circular; therefore the solution velocity in the center of the cell is steady and constant, and the crystals taken here would undergo the same condition and 
thus repeatable experiments are facilitated. The 74900 Series syringe pump (Cole-Parmer Instrument Company, USA) which are more precise than peristaltic pumps $[15,16]$, was used to control the solution flow rates. The growth of the crystal was observed by a DIAPHOT 300 inverted microscope (Nikon Company, Japan), monitored by CCD and recorded by video. The experiment platform was set in a closed environment, as shown in figure 2 , and the temperature was controlled at $18.0 \pm 0.5^{\circ} \mathrm{C}$.

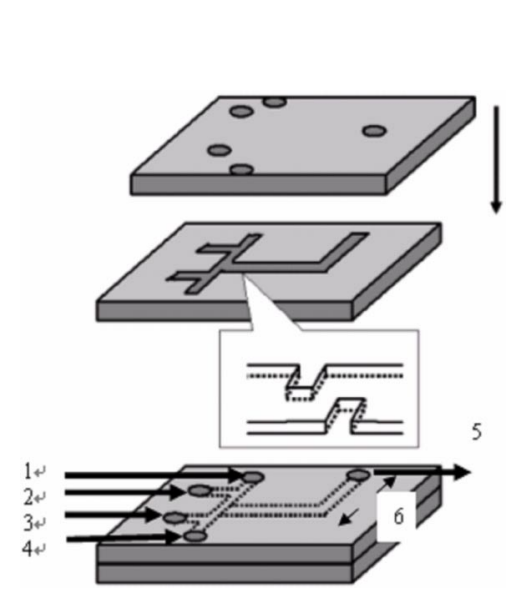

Fig. 1 The crystallization cell.

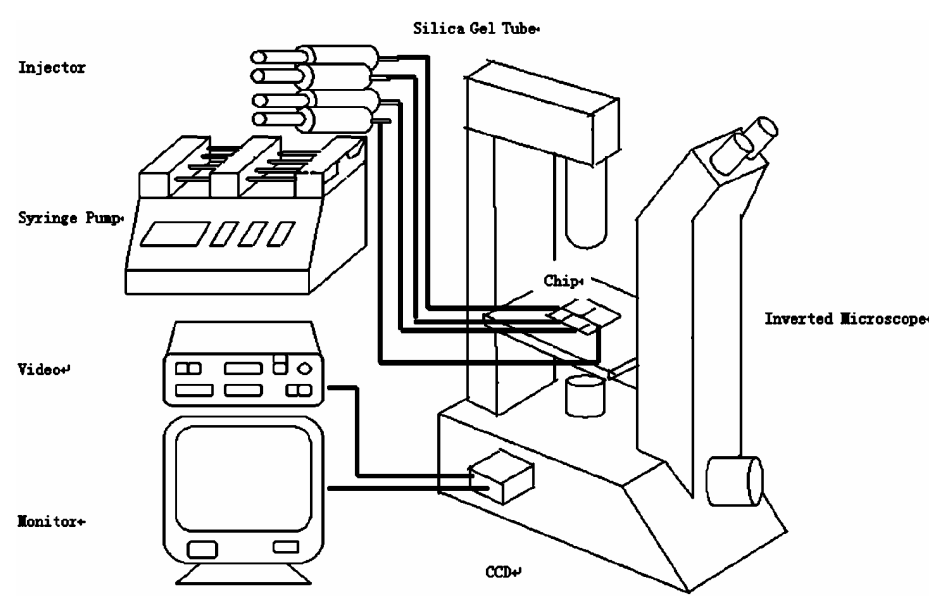

Fig. 2 The experiment platform.

The microchannel was first modeled by software named Fluent, meshes were marked off and proper wall conditions, boundary conditions, entrance conditions and initialization conditions were set. Here the entrance conditions were so set that the lysozyme and $\mathrm{NaCl}$ flowed into the channel with a flow rate ratio of 1:1.

In the computation, the solutions flowing into the channel were taken as follows: 1) $45 \mathrm{mg} / \mathrm{mL}$ lysozyme with a mass flow-rate $1.8 \mathrm{E}-5 \mathrm{~kg} / \mathrm{s}, 2) 14 \% \mathrm{NaCl}$ with a mass flow-rate $5.6 \mathrm{E}-5 \mathrm{~kg} / \mathrm{s}, 3) 45 \mathrm{mg} / \mathrm{mL}$ lysozyme with a mass flow-rate $1.8 \mathrm{E}-5 \mathrm{~kg} / \mathrm{s}, 4) 14 \% \mathrm{NaCl}$ with a mass flow-rate $5.6 \mathrm{E}-5 \mathrm{~kg} / \mathrm{s}$. Under these conditions, the solutions were flowing into the channel with a flow rate of $4.8 \mu \mathrm{l} / \mathrm{min}$, and the simulation result was shown in figure 3.
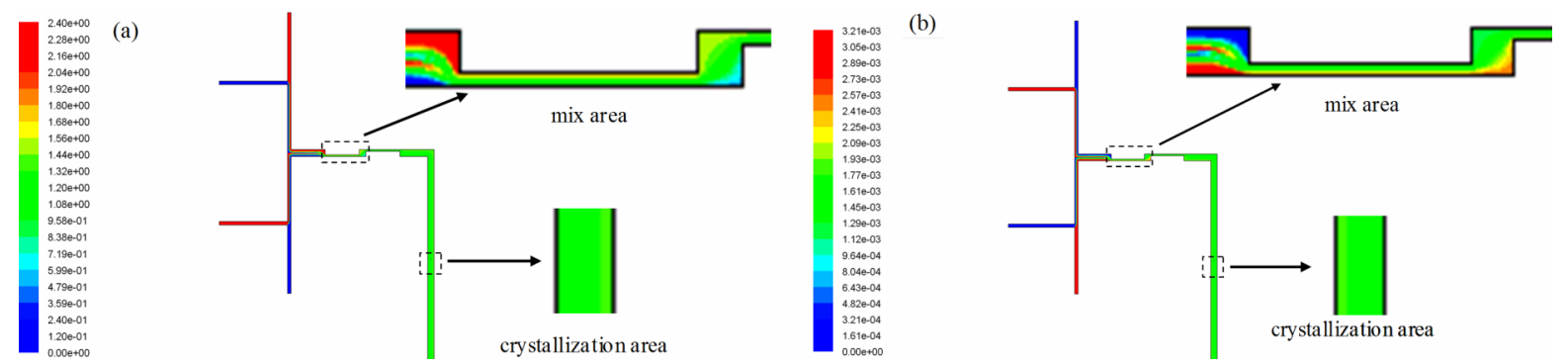

Fig. 3 (a) Contours of Molar Concentration of lysozyme. (b) Contours of Molar Concentration of NaCl. In the channel, the average flow velocity was $1600 \mu \mathrm{m} / \mathrm{s}$. (Online color at www.crt-journal.org)

From the contours of molar concentration, the concentrations of lysozyme and $\mathrm{NaCl}$ in the tail segment were distributed in the range of $22.5 \pm 2.2 \mathrm{mg} / \mathrm{mL}$ and $70 \pm 7.1 \mathrm{mg} / \mathrm{mL}$, respectively. When $45 \mathrm{mg} / \mathrm{mL}$ lysozyme and $14 \% \mathrm{NaCl}$ were mixed in the experiment with a flow rate ratio of $1: 1$, the perfect concentrations were $22.5 \mathrm{mg} / \mathrm{mL}$ and $70 \mathrm{mg} / \mathrm{mL}$, and thus the mixing effect of the microchannel mixer is acceptable.

In order to test the mixing effect, rhodamine $\mathrm{B}$ and deionized water were injected into the microchannel with a flow rate ratio of 1:1, and the results were shown in figure 4 . After testing with different flow rates, the mixing results of using the microchannel were satisfactory.

The buffer solution was filtrated with a $0.22 \mu \mathrm{m}$ filtration membrane before experiments, and proper amount of lysozyme powder and $\mathrm{NaCl}$ were dissolved in the buffer solution respectively. These solutions were kept at $4{ }^{\circ} \mathrm{C}$, and only the upper clear lysozyme solution was used. The lysozyme solution flowed into the microchannel from entrances 1,3 and $\mathrm{NaCl}$ solutions flowed from entrances 2 and 4 , the exit is 5 . In the 
experiments, the temperature was kept at $18.0 \pm 0.5^{\circ} \mathrm{C}$, the lysozyme and $\mathrm{NaCl}$ solutions were mixed with the same flow rate ratio. After the microchannel was full of solution, the forced flows were stopped for the lysozyme crystals to be produced. Then appropriate crystals were selected for observation, meanwhile the forced flows were restarted. The appropriate lysozyme crystals were located in the middle position and close to the tail of the microchannel, in which two of the (110) faces were parallel to the flow direction and two of them were vertical to the flow direction. Under these conditions, the effect of the flow field on the crystal growth remained unchanged at the same flow rate. In schematic diagram (Fig. 5), a segment of microchannel was shown together with the position where the appropriate crystal was taken, and an appropriate lysozyme crystal is shown in figure 6.

Fig. 4 The mixed results with the flow rate of $1600 \mu \mathrm{m} / \mathrm{s}$. (a) The result of the meeting. (b) The result of the tail.

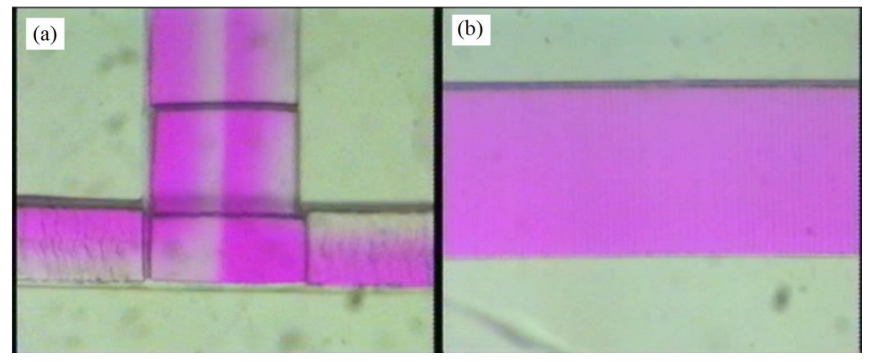

Fig. 5 The position of the crystal.

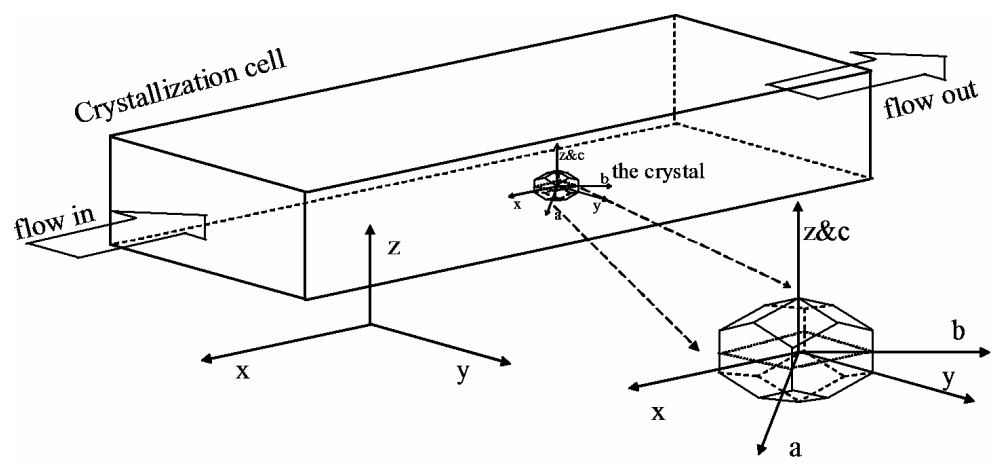

The Flowing Direction

The Flowing Rate: $2000 \mu \mathrm{m} / \mathrm{s}$

Fig. 6 The lysozyme crystal observed. Supersaturation $\sigma=2.7$, $\mathrm{NaCl} 7 \%(50 \mathrm{mmol} / \mathrm{L}, \mathrm{pH}=4.5)$, Temperature: $18.0 \pm 0.5{ }^{\circ} \mathrm{C}$, Flow rate: $2000 \mu \mathrm{m} / \mathrm{s}$, after $30 \mathrm{~min}$ under forced solution. The staff gauge was $100 \mu \mathrm{m}$.

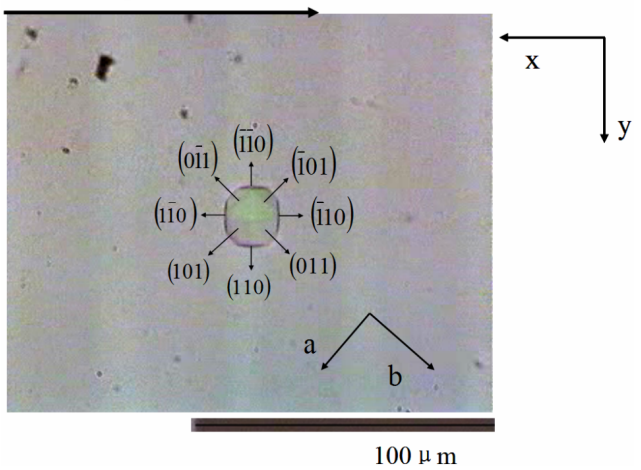

Under the conditions mentioned above, the supersaturation was calculated by $\sigma=\ln \left(C / C_{\text {equ }}\right)$, where $C$ is the lysozyme concentration and $C_{\text {equ }}$ is the equilibrium concentration. In all the experiments, the consumption of lysozyme solution was lower than $3 \mathrm{~mL}$.

The images recorded by video were processed in the following way: In every picture, a list of pixel values going through (110) face were selected, and these lists of pixel were rearranged to produce a new time-space image [24], in which the horizontal axis indicated the space between the two opposite (110) faces and the vertical axis indicated the time. From the time-space image, the reciprocal of the gray curve slope represents the instantaneous growth rate of (110) face, and thus the fluctuation of the growth rates can be clearly displayed. The protein heterogeneities of lysozyme (AMRESCO, Lot\#:2436B048, USA) were identified and quantified by sodium dodecyl sulfate polyacrylamide gel electrophoresis (SDS-PAGE) with silver staining 
protocol [25], and thin layer chromatography (TLC). SDS-PAGE was carried out with a Mini-PRTEAN electrophoresis unit (Bio-rad Company, USA). Silver staining solution (Beyotime Company, China) was used, and thin layer chromatography (TLC) was carried out with a CS-930 unit (SHIMADZU, Japan).

Dynamic Light Scattering (DLS) measurements to determine the distribution of aggregate in solution were carried out using the Spectroscatter 201 (RINA Company, Germany). The temperature was controlled at $18.0^{\circ} \mathrm{C}$. The acquisition of the experiment data was controlled automatically by a computer and processed with the software Spectro.

\section{Results and discussion}

The protein heterogeneities of lysozyme (AMRESCO, Lot\#:2436B048, USA) were identified and quantified by SDS-PAGE with silver staining protocol and TLC. The result indicated that the purity of the lysozyme purchased from AMRESCO Company is $94.7 \%$. The purity and the species of impurities in this article are the same as the lowly purified lysozyme that Rosenberger et al. [13] used in their experiment.

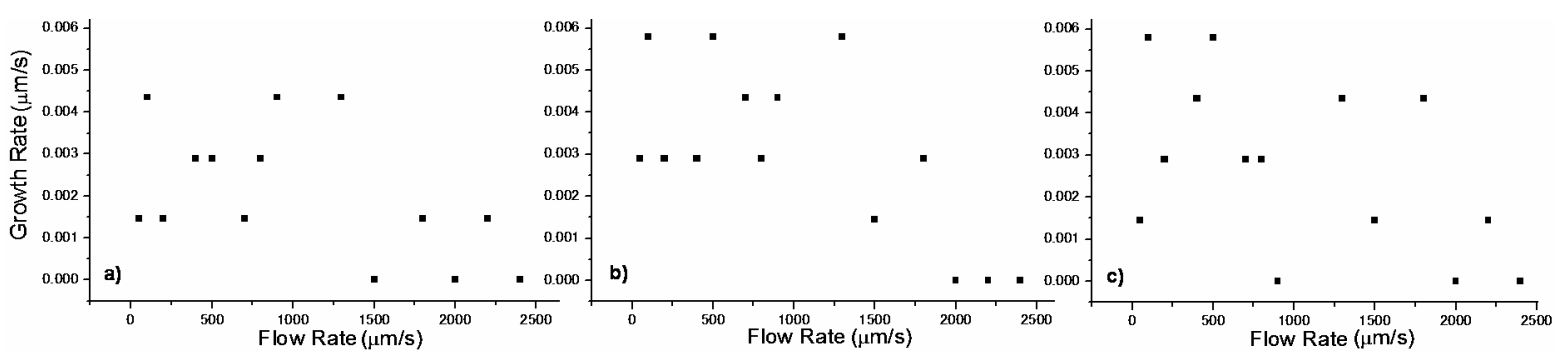

Fig. 7 Variation of the growth rates of (110) face with the flow rates at $\sigma=2.3, \mathrm{HAC}-\mathrm{NaAC}(50 \mathrm{mmol} / \mathrm{L}, \mathrm{pH}=4.5), \mathrm{NaCl}$ $7 \%, 18.0 \pm 0.5^{\circ} \mathrm{C}$. The (110) faces was parallel to the flow direction, and the size of the crystal was $19.6 \mu \mathrm{m}$. (a) The headon $(01 \overline{1})$ face; (b) the parallel (110) face ; (c) the rear (1 10$)$ face.

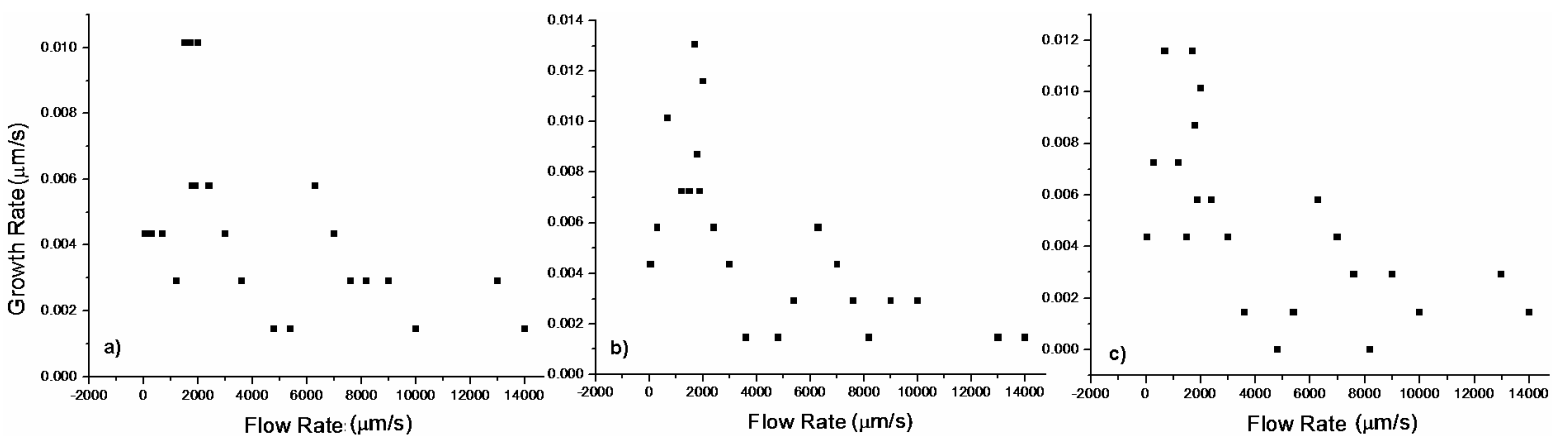

Fig. 8 Variation of the growth rates of (110) face with the flow rates at $\sigma=2.7$, HAC-NaAC $(50 \mathrm{mmol} / \mathrm{L}, \mathrm{pH}=4.5)$, $\mathrm{NaCl} 7 \%, 18.0 \pm 0.5^{\circ} \mathrm{C}$. The (110) faces was parallel to the flow direction, and the size of the crystal was $19.6 \mu \mathrm{m}$. (a) The head-on $(01 \overline{1})$ face; (b) the parallel (110) face; (c) the rear $(1 \overline{1} 0)$ face.

Different flow rates were selected in the experiments described above. In figure 7 , the image indicated the trend of the growth rates of the (110) face with increasing flow rates when the solution supersaturation was 2.3. The (110) faces were classified on the basis of the forced flow direction, including the head-on (011) face, the parallel (110) face and the rear (110) face. The experiments showed that with increase flow rates the growth rates hardly changed before the flow rates reached $1300 \mu \mathrm{m} / \mathrm{s}$, and decreased quickly afterwards. When the flow rate approached $2000 \mu \mathrm{m} / \mathrm{s}$, the crystal nearly ceased to grow.

When the supersaturation is $\sigma=2.7$, with increasing flow rate, the (110) face growth rates increase at the beginning, reach the biggest values at $1700 \mu \mathrm{m} / \mathrm{s}-1900 \mu \mathrm{m} / \mathrm{s}$, and decrease afterwards, approaching approximately zero when the flow rate reaches $12000 \mu \mathrm{m} / \mathrm{s}$ as shown in figure 8 .

Obviously, with different supersaturation, the variation trends of the growth rates of (110) face versus the flow rates are different. The experimental results also indicated that the flow rates at which the crystal ceases to grow evidently increased with the increase of supersaturation, and the flow rates corresponding to the highest 
growth rates vary with the size of the crystal. For instance, the flow rate corresponding to the highest growth rate is $1700 \mu \mathrm{m} / \mathrm{s}$ when the size of the crystal is $19.6 \mu \mathrm{m}$, and it is $1800 \mu \mathrm{m} / \mathrm{s}$ and $1900 \mu \mathrm{m} / \mathrm{s}$ when the size of crystal is $26 \mu \mathrm{m}$ and $39 \mu \mathrm{m}$, respectively. It was thought that the larger the size of crystal, the larger the flow rate corresponding to the highest growth rate.

The measurements in figures 7 and 8 show quite a lot of spread because the measurements were performed to different crystals which had the same sizes. Different crystals have different dislocation or two-dimensional nucleation densities leading to different growth rates. The time-space images were processed as mentioned in 2 , and the growth rates of (110) face under different flow rates were shown in figure 9.

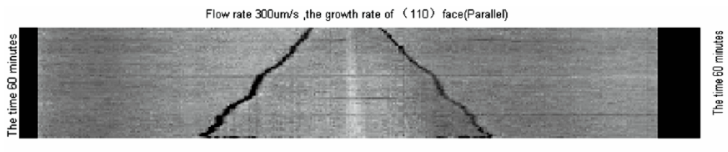

The size of crystal

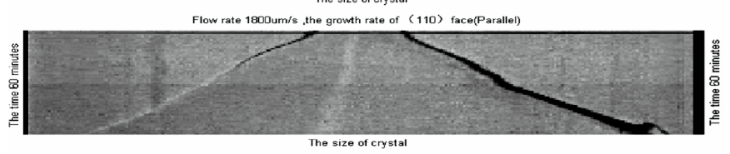

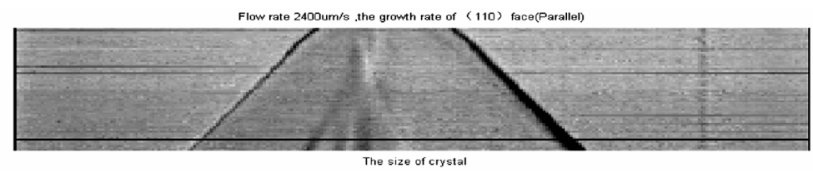

Flow rate $14000 \mathrm{um} / \mathrm{s}$, the growth rate of (110) taces(Parallal)

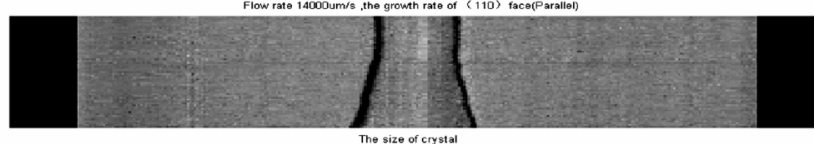

Fig. 9 The time-space images. $\sigma=2.7, \mathrm{NaCl} 7 \%$, $\mathrm{HAC}-\mathrm{NaAC}(50 \mathrm{mmol} / \mathrm{L}, \mathrm{pH}=4.5), 18.0 \pm 0.5^{\circ} \mathrm{C}$. The time-space images show the growth of (110) faces (parallel to the direction of the forced solution) in one hour, the horizontal axis corresponds to size of the crystal, and the vertical axis corresponds to time.
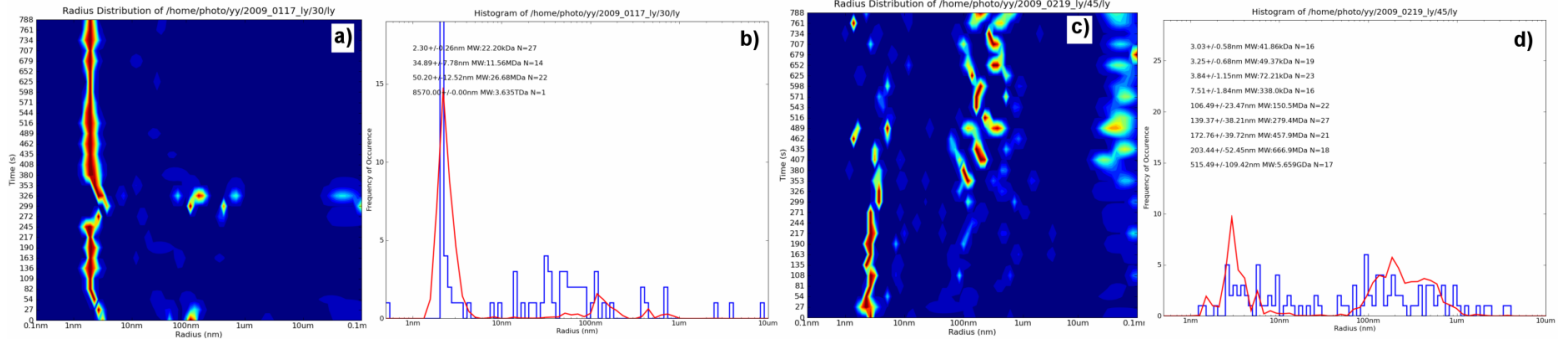

Fig. 10 The distribution of aggregate with different supersaturation. HAC-NaAC (50 mmol/L, $\mathrm{pH}=4.5), \mathrm{NaCl} 7 \%$, $18.0^{\circ} \mathrm{C}$, (a) and (b) $\sigma=2.3$, (c) and (d) $\sigma=2.7$. (Online color at www.crt-journal.org)

Rosenberger et al. $[13,15]$ figured that the growth rate depended on the flow rates and the purity of lysozyme. For the lysozyme with lower purity $(\approx 95 \%)$, the growth rates of $(101)$ face $[15,16]$ and $(110)$ face [13] would decrease with increasing flow rates, whereas for the lysozyme with higher purity $(\approx 99.99 \%)$, with increasing flow rates the growth rates would increase at the beginning, reach the maximum and then decrease. In this article, although the purity of lysozyme and the species of impurities are the same as the lower purity lysozyme that Rosenberger et al. [13] used in their experiment, the results are different. It was concluded that at higher supersaturation, even though the content of impurity is quite high, the crystal growth rates will still increase with the increase of the flow rates.

It is well known that at high supersaturations the influence of impurities on crystal growth rates is less than at low supersaturations [26,27]. When the growth rate normal to the interface is slow, the step growth rate is less than the rate which impurities are incorporated into a crystal. The concentration of impurities on the crystal surface is saturated. When the face growth rate is fast, the concentration of impurities on the crystal surface is not saturated. The forced solution is responsible for supplying the impurity and lysozyme molecules to near the crystal surface. The supersaturation in experiments conducted by Rosenberger et al. [13,15], was low, resulting in the reduction of the growth rates of (110) face with increasing flow rates . In this article, the supersaturation is high, so the growth is fast. Thus the growth rates of (110) face increase with the increase of flow rates. The reason why the forced flow makes the crystal cease to grow needs further studies. Maybe the flow rates affect the single molecule, the aggregates of lysozyme and the impurities near the crystal. The DLS results are shown in figure 10, where the $\mathrm{X}$ axis indicates the radius of aggregate grains, the $\mathrm{Y}$ axis of a and $\mathrm{c}$ indicates time and the $\mathrm{Y}$ axis of $\mathrm{c}$ and $\mathrm{d}$ indicates the frequency of occurrence. In figure 10a and $\mathrm{c}$, the color indicates the frequency of occurrence. As the frequency of occurrence is proportional to the number of the grains, the figure $10 \mathrm{~b}$ and $\mathrm{d}$ can indicate the ratios of different lysozyme aggregate grains. In figure 10b, the grain radius 
correspond to the strongest frequency of occurrence is $2.30 \mathrm{~nm}$. The number of macro aggregate grains in figure $10 \mathrm{~d}$ is more then it in figure $10 \mathrm{~b}$, and the macro aggregate grains were increasing quickly that also prove the crystal growth with the supersaturation $\sigma=2.7$ is fast. Nadarjah et al. [28] figured that the growing unit for the (110) face may be octamer corresponding to $4_{3}$ helix while the growing unit for the (101) face may be tetramer corresponding to $4_{3}$ helix [29]. It was concluded that with the supersaturation $\sigma=2.7$, the number of octamers and those lysozyme aggregates is larger than that with the supersaturation $\sigma=2.3$.

When the flow rates are low, persistently forced solution flow could increase the supply of lysozyme which can enter the crystal. But when the flow rate is too high, it might affect the distribution of the lysozyme aggregates near the crystal, which might make the octamer difficult to be incorporated into the crystal, and thus the growth rate of (110) face became lower.

\section{Conclusions}

After a series of experiments and related modeling, conclusions are drawn as follows: Newly designed equipment, which uses a microchannel mixer of rectangular section as the crystallization container, is proved to be effective for facilitating repeatable experiments and precise control of the flow rates. Forced solution flows enhance the protein, as well as the impurity, transferred to the crystal. Under different supersaturations, the effects of forced flows on the lysozyme crystal are different. When the supersaturation is low, the forced flow might reduce the crystal growth rate. When the supersaturation is high, low flow rate would promote the crystal growth but high flow rate would hinder the crystal growth. The higher the supersaturation, the larger the flow rate at which the crystal ceases to grow.

Acknowledgement The work was supported by the National Natural Science Foundation of China (Grant Nos. 10472127 and 10432060) and the Knowledge Innovation Program of the Chinese Academy of Sciences (Grant No. KJCX2-YW-L08).

\section{References}

[1] S. Miyashita, H. Komatsu, Y. Suzuki, and T. Nakada, J. Cryst. Growth 141, 419 (1994).

[2] M. Pusey, W. Witherow, and R. Naumann, J. Cryst. Growth 90, 105 (1998).

[3] M. Kawaji, O. Gamache, D. H. Hwang, N. Ichikawa, J. P. Viola, and J. Sygusch, J. Cryst. Growth 258, 420 (2003).

[4] A. McPherson, Cold Spring Harbor (Cold Spring Harbor Laboratory Press, New York, 1999) p. 437.

[5] R. C. Bi, Chin. J. Space Sci. 16, 208 (1996).

[6] L. J. DeLucas, C. D. Smith, D. C. Carter et al., Adv. Space Res. 12, 393 (1992).

[7] R. C. Bi, L. L. Gui, K. Shi et al., Sci. China Ser. B 23, 1153 (1993).

[8] P. Bhattacharjee and D. N. Riahi, Microgravity Sci. Tec. XIV/4, 36 (2003).

[9] M. Pusey, W. Witherow, and R. Naumann, J. Cryst. Growth 90, 105 (1988).

[10] A. Thomas and F. Rosenberger, J. Cryst. Growth 110, 52 (1991).

[11] M. L. Grant and D. A. Saville, J. Cryst. Growth 108, 8 (1991).

[12] H. Lin, F. Rosenberger, J. I. D. Alexander, and A. Nadarajah, J. Cryst. Growth 151, 153 (1995).

[13] P. G. Vekilov, F. Rosenberger, H. Lin, and B. R. Thomas, J. Cryst. Growth 196, 261 (1999).

[14] H. L. Cui, Y. Yu, W. C. Chen, and Q. Kang, Chin. Sci. Bull. 52, 1196 (2007).

[15] P. G. Vekilov and F. Rosenberger, J. Cryst. Growth 186, 251 (1998).

[16] P. G. Vekilov, B. R. Thomas, and F. Rosenberger, J. Phys. Chem. B 102, 5208 (1998).

[17] A. Kadowaki, I. Yoshizaki, L. Rong, H. Komatsu, O. Odawara, and S. Yoda, J. Synchrotron Rad. 11, 38 (2004).

[18] A. Kadowaki, I. Yoshizaki, S. Adachi, H. Komatsu, O. Odawara, and S. Yoda, Cryst. Growth Des. 6, 2398 (2008).

[19] L. Rong, I. Yoshizaki, H. Komatsu, A. Kadowaki, S. Fukuyama, Y. Limura, and S. Yoda, J. Jpn. Soc. Microgravity Appl. 28, 128 (2003).

[20] E. Curcio, S. Simone, G. D. Profio, E. Drioli, A. Cassetta, and D. J. Lamba, Membr. Sci. 257, 134 (2005).

[21] C. L. Hansen, E. Skordalakes, J. M. S. Berger, and R. Quake, PNAS 99, 16531 (2002).

[22] M. Schramboeck, W. Schrenk, T. Roch, A. M. Andrews, M. Austerer, and G. Strasser, Micro. Eng. 83, 1673 (2006).

[23] B. Zheng, J. D. Tice, and R. F. Ismagilov, Adv. Mater. 16, 1365 (2004).

[24] P. Dold, E. Ono, K. Tsukamoto, and G. Sazaki, J. Cryst. Growth 293, 102 (2006).

[25] B. R. Thomas, P. G. Vekilov, and F. Rosenberger, Acta. Cryst. D 52, 776 (1996).

[26] G. D. Botsaris, E. A. Mason, and R. C. Reid, AIChE J. 13, 764 (1967).

[27] K. Sangwal, Additives and Crystallization Processes, from Fundamentals to Applications (John Wiley \& Sons, Chichester, England, 2007).

[28] A. Nadarajah, L. Meirong, and M. L. Pusey, Acta Cryst. D 53, 524 (1997).

[29] L. Meirong, A. Nadarajah, and M. L. Pusey, Acta Cryst. D 55, 1012 (1999). 